\title{
Upaya Peningkatan Hasil Belajar Bahasa Indonesia Melalui Media Video Pembelajaran Pada Siswa Kelas II SD
}

\section{Dwi Hastuti}

SD 4 Payaman

hastutidwi267@gmail.com

\section{Article History}

accepted 01/11/2020

\begin{abstract}
The purpose of this study was to improve the learning outcomes of class II students in Indonesian language learning. The research was conducted in three cycles, and each cycle was divided into one meeting. Each cycle consists of planning, implementing, observing and reflecting. Data collection techniques are observation and tests. Based on the data analysis, it was found that the use of video media in Indonesian learning with vocabulary materials and concepts could improve student learning outcomes as indicated by the level of learning completeness in the initial conditions of $30 \%$ to $60 \%$ in cycle I, and increased to $80 \%$ in cycle II. and increased to $85 \%$ in cycle III. The final conclusion from the implementation of this classroom action research is that the use of video media is able to improve student learning outcomes in learning Indonesian vocabulary materials and concepts in SD 4 Payaman, Mejobo District, Kudus Reg
\end{abstract}

Keywords: Video media, learning outcomes

\section{Abstrak}

Tujuan penelitian ini adalah meningkatkan hasil belajar peserta didik kelas II pada pembelajaran Bahasa Indonesia. Penelitian dilakukan dengan tiga siklus, dan tiap siklus dibagi menjadi satu kali pertemuan. Setiap siklus terdiri dari tahap perencanaan, pelaksanaan, observasi dan refleksi. Teknik pengumpulan data adalah observasi dan tes. Berdasarkan analisis data, diperoleh hasil bahwa penggunaan media video pada pembelajaran Bahasa Indonesia materi kosakata dan konsep dapat meningkatkan hasil belajar peserta didik yang ditunjukkan dengan tingkat ketuntasan belajar pada kondisi awal $30 \%$ menjadi $60 \%$ pada siklus I, dan meningkat menjadi $80 \%$ pada siklus II dan meningkat menjadi $85 \%$ pada siklus III. Kesimpulan akhir dari pelaksanaan penelitian tindakan kelas ini adalah penggunaan media video mampu meningkatkan hasil belajar peserta didik pada pembelajaran Bahasa Indonesia materi kosakata dan konsep di SD 4 Payaman Kecamatan Mejobo Kabupaten Kudus.

Kata kunci: Media video, hasil belajar

Social, Humanities, and Education Studies (SHEs): Conference Series https://jurnal.uns.ac.id/shes 


\section{PENDAHULUAN}

Mata pelajaran Bahasa Indonesia merupakan mata pelajaran yang dianggap mudah tapi ternyata sulit bagi siswa dalam pembelajaran di kelas. Selain itu terkadang Bahasa Indonesia juga merupakan pelajaran yang membosankan. Hal ini dikarenakan media yang digunakan terlalu monoton atau kurang menarik minat siswa dalam pembelajaran. pada awal pembelajaran seharusnya guru memfokuskan perhatian siswa pada pembelajaran tetapi yang terjadi malah guru langsung masuk pada pembelajaran dan tidak menghiraukan siswa yang masih asyik mengobrol sendiri. Hal ini mengakibatkan perhatian siswa masih belum tertuju pada pembelajaran dan guru mengabaikannya. Permasalahan juga ditemukan ketika pembelajaran yang dilakukan guru masih belum bisa mengkaitkan antara materi yang akan dipelajari dengan pengalaman yang dimiliki siswa.

Guru juga belum mengemukakan manfaat yang diperoleh siswa setelah mempelajari materi tersebut. Akibatnya pembelajaran yang dilakukan tidak begitu bermakna bagi siswa. Hal ini dikarenakan siswa tidak memahami akan manfaat yang ia peroleh nantinya jika ia mau mempelajari materi tersebut. Di sisi lain guru hanya menggunakan RPP yang sudah ada sehingga guru kurang memiliki gaya mengajar dan pola interaksi yang variatif. Kondisi ini menyebabkan kejenuhan dan suasana kelas menjadi pasif selama pembelajaran.

Untuk mengatasi kendala tersebut, maka penulis mencoba melakukan perbaikan pembelajaran menggunakan media video. Media video adalah merupakan rangkaian gambar elektronis yang disertai oleh unsur suara serta unsur gambar yang diputar dengan suatu alat (Ronal Anderson, 1994). Hal ini merupakan strategi untuk mendukung pembelajaran daring. Media pembelajaran video terbuki dapat meningkatkan hasil belajar (Yuniarti, 2015)

Berdasarkan uraian diatas peneliti mencoba melakukan penelitian dengan judul Upaya peningkatan hasil belajar bahasa indonesia melalui media video pembelajaran pada siswa kelas II SD 4 Payaman Kecamatan Mejobo Kabupaten Kudus.

Tujuan penelitian ini adalah Untuk meningkatkan hasil belajar peserta didik dengan penggunaan media pembelajaran video pada materi menentukan kosakata dan konsep kelas II SD 4 Payaman Tahun 2020/2021.

\section{METODE}

Penelitian ini merupakan penelitian tindakan kelas (PTK) kolaboratif yang dilaksanakan dalam tiga siklus, setiap siklus terdiri dari tahap perencanaan, pelaksanaan, observasi dan refleksi. Subyek penelitian ini adalah siswa kelas II SD 4 Payaman Tahun Pelajaran 2020/2021 yang berjumlah 10 peserta didik. Data yang dianalisis berupa data kualitatif yaitu penggunaan media video pembelajaran dan data kuantitatif yaitu hasil belajar bahasa indonesia peserta didik. Teknik pengumpulan data menggunakan observasi dan tes. Analisis data meliputi reduksi data, menggunakan triangulasi teknik dan triangulasi sumber. Analisis data meliputi reduksi data, penyajian data, dan penarikan kesimpulan.

\section{HASIL DAN PEMBAHASAN}

Berdasarkan analisis hasil penelitian yang telah diuraikan telah menunjukkan peningkatan hasil belajar pada materi kosakata dan kosep terlihat pada tabel berikut : 
Tabel 1. Peningkatan Hasil Belajar

\begin{tabular}{lllllll}
\cline { 2 - 3 } Nilai & Siklus I & & Siklus II & \multicolumn{2}{c}{ Siklus III } \\
\hline & $\mathrm{f}$ & $\%$ & $\mathrm{~F}$ & $\%$ & $\mathrm{f}$ & $\%$ \\
\hline 100 & 2 & 20 & 4 & 40 & 5 & 50 \\
\hline 75 & 4 & 40 & 4 & 40 & 4 & 40 \\
\hline 50 & 3 & 30 & 2 & 20 & 1 & 10 \\
\hline 25 & 1 & 10 & & & & \\
\hline 0 & & & & & & \\
\hline Jumlah & 10 & & 10 & & 10 & \\
\cline { 2 - 6 } Rata-rata & 67 & & 80 & & 85 & \\
\hline Tuntas & 6 & 60 & 8 & 80 & 9 & 90 \\
\hline
\end{tabular}

Penelitian yang dilakukan di Sekolah Dasar 4 Payaman, bertujuan untuk meningkatkan hasil belajar muatan pelajaran Bahasa Indonesia siswa kelas II. Penelitian dilaksanakan mulai dari pratindakan, tindakan siklus I, tindakan siklus II dan tindakan siklus III. Media yang dipilih dalam penelitian ini adalah media video pembelajaran. Dari penelitian ini dapat dijelaskan bahwa penggunaan media video pembelajaran dapat meningkatkan hasil belajar muatan pelajaran Bahasa Indonesia siswa kelas II SD 4 Payaman.

Hasil dari tindakan siklus I, persentase ketuntasan siswa 60\%. Dari 10 siswa, sebanyak 6 siswa mencapai ketuntasan. Siswa yang belum mencapai ketuntasan sebanyak 4 siswa. Banyaknya siswa yang belum mencapai ketuntasan karena mereka belajar dengan kurang serius. Guru telah memberi motivasi agar meningkatkan semangat dalam belajar. Setelah tindakan siklus II naik menjadi $80 \%$. Ketuntasan belajar, sebanyak 8 siswa dapat mencapai batas ketuntasan, dan 2 siswa belum mencapai ketuntasan. Pada tindakan siklus III naik menjadi $85 \%$. Ketuntasan belajar sebanyak 9 siswa dan 1 siswa belum mencapai ketuntasan. Satu siswa yang belum mencapai ketuntasan, disebabkan karena memang siswa berjenis slowlearner yang membutuhkan tambahan waktu dan perhatian khusus dalam mendampingi mereka belajar. Kriteria keberhasilan penelitian telah tercapai, maka tindakan sampai siklus III.

\section{SIMPULAN}

Berdasarkan hasil penelitian dan pembahasan pada bab sebelumnya, dapat disimpulkan bahwa penggunaan media video untuk pembelajaran pada materi kosakata dan konsep siswa kelas II semester 1 SD 4 Payaman Kecamatan Mejobo Kabupatn Kudus Tahun Pelajaran 2020/2021 terbukti dapat meningkatkan hasil belajar siswa Selanjutnya dapat disimpulkan bahwa media video dapat meningkatkan hasil belajar siswa dalam materi kosakata dan konsep dengan hasil evaluasi pada siklus 1 rata-rata hanya 67, pada siklus II meningkat menjadi 80 , siklus III meningkat lagi 85 . Serta ketuntasan belajarnya juga mengalami peningkatan dari siklus 1 sebesar $60 \%$, siklus sebesar II 80\%, dan siklus III sebesar $90 \%$.

\section{DAFTAR PUSTAKA}

Anshor, Shokhibul. 2015. Penggunaan Media Pembelajaran Berbasis Video. https://medianeliti.com/2015/Penggunaan-Media- Pembelajaran-Berbasis Video. Diunduh 13 Oktober 2020 
Arikunto, Suharsimi. 2003. Penelitian Tindakan Kelas. Jakarta: Bumi Aksara. Artikelsiana. 2017. Pengertian Prestasi, Macam \& Prestasi Menurut Para Ahli.

http://www.artikelsiana.com/2017/11/pengertian-prestasi-macam- prestasi.html. Diunduh Jumat, 28 September 2018, Pukul 10.00 WIB.

Al-Hafizh, Mushlihin. 2012. Pengertian Kosakata. http://www.referensimakalah.com

/2012/07/pengertian-kosakata.html. Diunduh Selasa, 13 Oktober 2020, Pukul 10.00 WIB.

Habibah, Syarifah. Oktober 2016. Penggunaan Model Pembelajaran Examples Non Examples TerhadBABap Ketuntasan Hasil Belajar Siswa Pada Materi TokohTokoh Pergerakan Nasional Kelas V SDN 70 Banda Aceh, Jurnal Pesona Dasar Universitas Syiah Kuala Vol. 3 No.4, http://www.jurnal.unsyiah.ac.id/PEAR/article/download/7541/6208,

September 2018

Hariyanto. 2010. Pengertian Prestasi Belajar. http://belajarpsikologi.com/pengertianprestasi-belajar/. Diunduh Selasa, 13 Oktober 2020 Pukul 10.00 WIB.

Sardiman. Interaksi dan Motivasi Belajar Mengajar. Jakarta: Raja-Grafindo Persada. Usman, U. 2010. Menjadi Guru Profesional. Bandung: Remaja Rosdakarya.

Yuniarti, Syamsiati, 2015. Peningkatan hasil belajar dengan media video pembelajaran IPA di Sekolah Dasar. 